\title{
Impact of subsoil constraints on wheat yield and gross margin on fine-textured soils of the southern Victorian Mallee
}

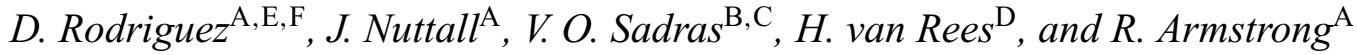 \\ A Primary Industries Research Victoria - Horsham, 110 Natimuk Rd, Horsham, Vic. 3400, Australia. \\ ${ }^{B}$ South Australian R\&D Institute (SARDI), Adelaide, SA, Australia. \\ ${ }^{\mathrm{C}}$ School of Agriculture and Wine, The University of Adelaide, Waite Campus, SA 5064, Australia. \\ ${ }^{D}$ Birchip Cropping Group, PO Box 85, Birchip, Vic. 3483, Australia. \\ ${ }^{\mathrm{E}}$ Current address: Department of Primary Industries and Fisheries, Agricultural Production Systems \\ Research Unit (APSRU), PO Box 102, Toowoomba, Qld, Australia. \\ FCorresponding author. Email: Daniel.Rodriguez@dpi.qld.gov.au
}

\begin{abstract}
The APSIM-Wheat module was used to investigate our present capacity to simulate wheat yields in a semi-arid region of eastern Australia (the Victorian Mallee), where hostile subsoils associated with salinity, sodicity, and boron toxicity are known to limit grain yield. In this study we tested whether the effects of subsoil constraints on wheat growth and production could be modelled with APSIM-Wheat by assuming that either: $(a)$ root exploration within a particular soil layer was reduced by the presence of toxic concentrations of salts, or $(b)$ soil water uptake from a particular soil layer was reduced by high concentration of salts through osmotic effects. After evaluating the improved predictive capacity of the model we applied it to study the interactions between subsoil constraints and seasonal conditions, and to estimate the economic effect that subsoil constraints have on wheat farming in the Victorian Mallee under different climatic scenarios. Although the soils had high levels of salinity, sodicity, and boron, the observed variability in root abundance at different soil layers was mainly related to soil salinity. We concluded that: $(i)$ whether the effect of subsoil limitations on growth and yield of wheat in the Victorian Mallee is driven by toxic, osmotic, or both effects acting simultaneously still requires further research, (ii) at present, the performance of APSIM-Wheat in the region can be improved either by assuming increased values of lower limit for soil water extraction, or by modifying the pattern of root exploration in the soil profile, both as a function of soil salinity. The effect of subsoil constraints on wheat yield and gross margin can be expected to be higher during drier than wetter seasons. In this region the interaction between climate and soil properties makes rainfall information alone, of little use for risk management and farm planning when not integrated with cropping systems models.
\end{abstract}

Additional keywords: root growth, salinity, sodicity, boron toxicity, El Niño, La Niña, ENSO.

\begin{abstract}
Introduction
Simulation modelling has proven to be important and valuable in improving crop management decisions (Meinke and Hochman 2000), optimising cropping systems (Robertson et al. 2000), quantifying environmental risks (Asseng et al. 1998), and evaluating the effect of climate variability and climate change (Hammer et al. 1996). However, subsoil limitations such as salinity or sodicity have so far limited the application of simulation models in regions such as the main cereal-growing areas of north-western Victoria. In this region, restrictions to root growth and water uptake have been attributed to high levels of salinity and sodicity (Rengasamy 2002), and even to toxic levels of soil boron (Holloway and Alston 1992). Simulation
\end{abstract}

exercises in the region have been published (O'Leary and Connor 1996a, 1996b); however, these studies were limited to non-saline soils from the Mallee and Wimmera regions. The effect of soil properties and crop type on plant-available water capacity requires the measurement of the crop lower limit (CLL). CLL has been defined as the volumetric soil water remaining in the soil after a healthy crop, with uninterrupted root development, has reached maturity under soil water-limited conditions (Hochman et al. 2001). Methods to determine CLL in the field are laborious, expensive, and site specific, which make them unsuitable to be used in precision agriculture. Precision agriculture requires modelling tools able incorporate spatial attributes of the landscape in a simple and inexpensive way such as from 
the determination of subsoil salinity from EM38 surveys (O'Leary et al. 2004). However, before this can be achieved a better understanding of the mechanisms linking subsoil constraints and crop growth and yield in simulation models is required. In this study we aim to: (i) test whether the effects of subsoil constraints on wheat growth and production can be modelled with APSIM-Wheat by assuming that either (a) root exploration within a particular soil layer is reduced by the presence of toxic concentrations of salts, or $(b)$ soil water uptake from a particular soil layer is reduced by high concentration of salts through osmotic effects; (ii) study the importance of the interactions between subsoil constraints and seasonal conditions; and (iii) quantify the economic effect of both subsoil constraints and climate variability in the Victorian Mallee of Victoria.

\section{Methods}

\section{Field experiments}

Data sets from wheat (Triticum aestivum L.) crops grown in on-farm experiments in the southern Mallee of Victoria, Australia, were obtained for the cropping seasons 1993, 1994, and 1999. During the first 2 years (Expt 1), soil and crop data were collected from 2 commercial crops at $\operatorname{Brim}\left(36.07^{\circ} \mathrm{S}, 142.42^{\circ} \mathrm{E}\right)$ and Birchip $\left(35.98^{\circ} \mathrm{S}, 142.92^{\circ} \mathrm{E}\right)$, and during 1999 (Expt 2), 16 sites were randomly selected from 150 surveyed sites (Nuttall et al. 2003a) covering an area of $3600 \mathrm{~km}^{2}$ in the Birchip district. The soils in the region are mainly Calcarosols (Nuttall et al. 2003a), and the long-term (1957-2002) average seasonal (1 April1 November) rainfall is $257 \mathrm{~mm}$.

\section{Field Expt 1}

During the 1993 and 1994 cropping seasons, 2 wheat fields (Triticum aestivum L. cv. Frame) from the Brim and Birchip areas were sampled to determine soil water, $\mathrm{N}-\mathrm{NO}_{3}(\mathrm{mg} / \mathrm{kg})$, organic carbon $(\%)$, electric conductivity $(\mathrm{EC}, \mathrm{dS} / \mathrm{m})$, bulk density $\left(\mathrm{g} / \mathrm{cm}^{3}\right)$, and $\mathrm{pH}$ at $0-0.1$, $0.1-0.6$, and $0.6-1 \mathrm{~m}$ depths. Crop data included date of anthesis, maximum rooting depth, grain yield, and above-ground biomass. After sowing the wheat crop in autumn 1993 the soil water content of the different soil layers was measured at about monthly intervals using a neutron moisture meter (Model 503, Campbell Pacific Nuclear Crop, Martinez, CA). Surface-layer soil water $(0-0.25 \mathrm{~m})$ was measured gravimetrically. Results are averages of 3-5 replications within each paddock.

\section{Field Expt 2}

Soil and crop data were collected from the Birchip district of Victoria, Australia (Nuttall et al. 2003a). The data set consisted of soil and crop characteristics determined in transects of 10 points at 15 locations, i.e. 150 sites, within a radius of $c .30 \mathrm{~km}$ around Birchip, collected during the 1999 season. At each site the following soil variables were determined at different depths in the soil profile: soil boron (mg B/kg soil), EC (dS/m), exchangeable sodium (ESP, \%), N-NO $(\mathrm{mg} / \mathrm{kg})$, volumetric soil water content at sowing, volumetric soil water content at wilting point (WP), and bulk density. Among others, crop variables included layered root dry weight at anthesis, and final grain yield.

\section{Simulation Expt 1}

The Agricultural Production Systems Simulator (APSIM) (McCown et al. 1996) allows the simulation of diverse crops and cropping systems targetting issues such as land degradation (Asseng et al. 2001), crop rotation (Carberry et al. 1996), cropping strategies
(Robertson et al. 2000), and management alternatives (Goyne et al. 1996). APSIM-Wheat (APSIM version 2.1 patch 2) has been tested against field studies in different regions of Australia and locally for this study. In this exercise we used the model APSIM-Wheat parameterised with modules SOILN2, SOILWAT2, and RESIDUE2. The phenology parameters of the model were calibrated for the wheat crop cv. Frame using an independent data set provided by Dr R. Flood (unpublished data). Values of soil water content at saturation (SAT) were calculated from values of bulk density (Dalgliesh and Foale 1998), values of drainage upper limit (DUL) were derived from a relationship between SAT and DUL determined from wet ponds in soils of the Mallee region, and soil water lower limits (LL) were taken as soil water contents determined in the laboratory at $-15 \mathrm{kPa}$ (WP). Wheat yields were simulated assuming: $(i)$ the observed root distribution within the soil profile at each site and measured values of LL15 as inputs to the model (Hypothesis A), (ii) ignoring the presence of subsoil constraints and using measured values of LL15 (control), (iii) calculating the root soil profile distribution from a function relating root distribution and EC (dS/m) (Hypothesis A), and (iv) calculating the value of the crop lower limit (parameter $l l$ in APSIM) for each soil layer, as a function of the EC $(\mathrm{dS} / \mathrm{m})$ as proposed by Sadras et al. (2003) (Hypothesis B). Within APSIM the effects of EC on root distribution were incorporated by modifying the value of the parameter ' $x f$ ', i.e. root exploration factor for each soil layer. The agreement between observed and simulated results was evaluated by comparing the coefficient of determination, root mean squared error, and by desegregating the mean squared error following the methodology proposed by Kobayashi and Salam (2000).

\section{Simulation Expt 2}

To study the interactions between subsoil constraints and seasonal conditions on grain yield and economic return at Birchip, we used crop lower limits (parameter $l l$ in APSIM) calculated as a function of EC $(\mathrm{dS} / \mathrm{m})$ as in Sadras et al. (2003). Historical climate data for the period 1900-2002 years (Birchip Post Office, station no. 77007), were obtained from the Silo Patched Point Data Set (http://www.bom.gov.au/silo). Simulated treatments included 3 levels of soil salinity, i.e. low (decile 1), median (decile 5), and high (decile 9) (see Fig. 1a). Simulation outputs are presented for all the simulated years and for those years defined as El Niño years and La Niña years (as in http://www.longpaddock.qld.gov.au). Gross margin in A $\$ / h a$ was estimated as the product of yield and price minus variable costs; we did not take into account fixed costs. Variable costs, including fertilisers, were set at $\mathrm{A} \$ 158.76 / \mathrm{ha}$, and included the cost of contracting machinery works (including harvest), seed, and chemicals. Grain price was calculated depending on grain quality following the Australian Wheat Board standards. Initial conditions for model simulations were reset every 1 January to $10 \%$ of plant-available water, $50 \mathrm{~kg} \mathrm{~N} / \mathrm{ha}$, and $1000 \mathrm{~kg} / \mathrm{ha}$ of canola residues from previous crop. Every year, $50 \mathrm{~kg} \mathrm{~N} / \mathrm{ha}$ were applied at sowing.

\section{Results}

\section{Subsoil constraints}

Figure 1 shows the main chemical and physical characteristics of the sites under study. In general terms the concentration and levels of variability in soil salinity, sodicity, and boron increased with soil depth, whereas the values of wilting point varied little. The 'regional' variability, i.e. coefficient of variation, $\%$, for each of these parameters at each of the soil depths was greatest for boron in the upper layers $(0-0.4 \mathrm{~m})$, and for salinity in the deeper layers $(0.4-1 \mathrm{~m})$ (Table 1 ). Interestingly the coefficients of variation for soil sodicity 

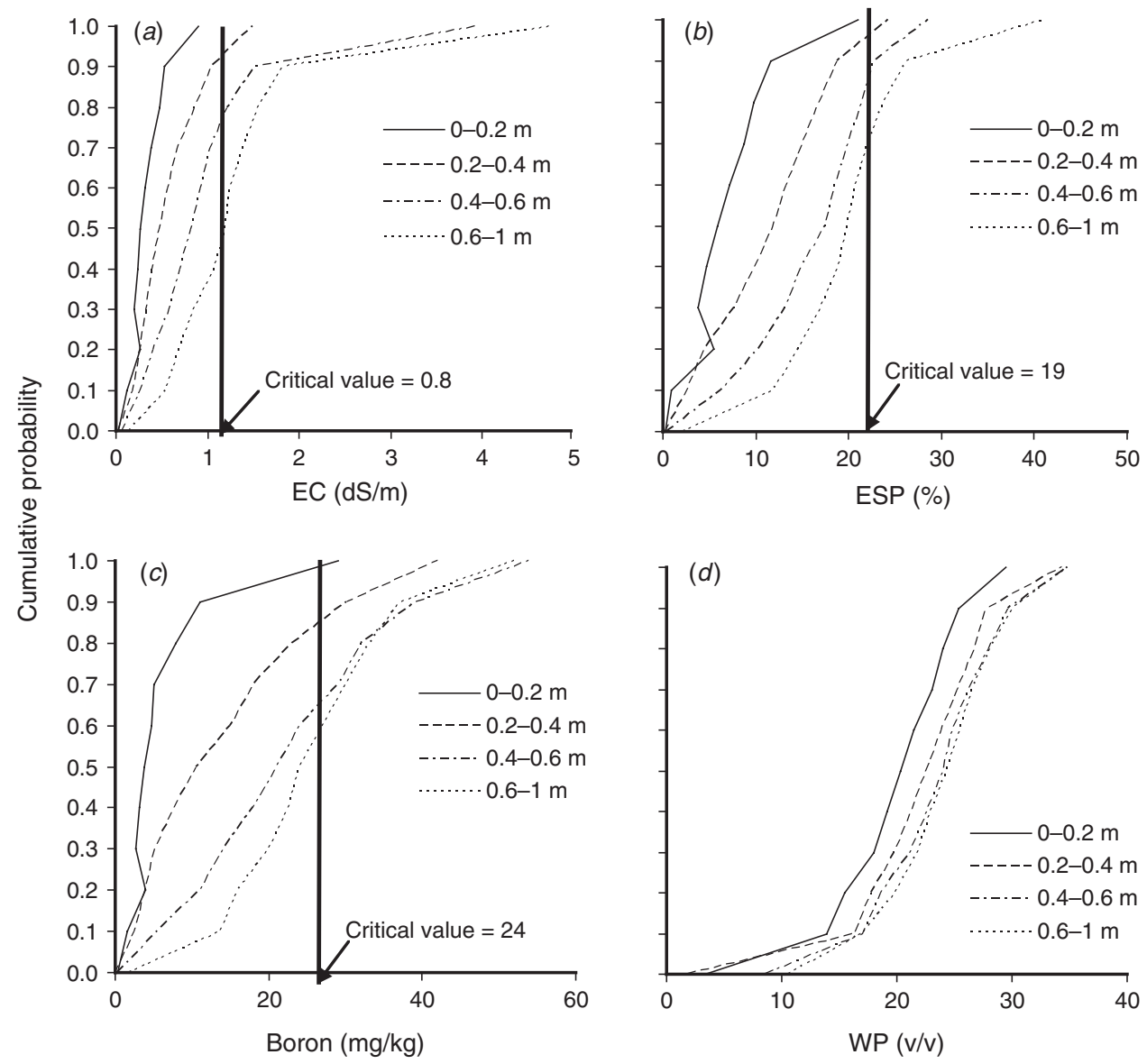

Fig. 1. Cumulative probability distribution of $(a)$ soil salinity, EC $(\mathrm{dS} / \mathrm{m}) ;(b)(\%)$ exchangeable sodium percentage, ESP; $(c)$ soil boron; and $(d)$ volumetric soil water content at $-15 \mathrm{kPa}$ (WP), at $0-0.2,0.2-0.4$, $0.4-0.6$, and 0.6-1 m depths from 150 sites around Birchip. Vertical lines in $a, b$, and $c$ indicate critical threshold values for grain yield. After Nuttall et al. (2003a).

Table 1. Coefficients of variation (\%) for salinity (EC), exchangeable sodium percentage (ESP), boron (B), cation exchange capacity (CEC), and soil water $-15 \mathrm{kPa}$ (WP), at different depths, observed in soil samples from the Birchip region (after Nuttall et al. 2003a)

\begin{tabular}{lccccc}
\hline Soil layer $(\mathrm{m})$ & EC & ESP & B & CEC & WP \\
\hline $0-0.2$ & 55.0 & 67.8 & 94.1 & 28.5 & 25.9 \\
$0.2-0.4$ & 59.4 & 54.2 & 79.5 & 19.3 & 24.0 \\
$0.4-0.6$ & 68.8 & 39.8 & 58.5 & 17.9 & 22.4 \\
$0.6-1$ & 54.8 & 33.7 & 40.0 & 17.1 & 20.0 \\
\hline
\end{tabular}

were highly correlated with the coefficients of variation for boron, cation exchange capacity, and soil lower limit (Table 2), but not with the coefficients of variation for soil salinity.

Frequency distributions of key soil chemical constraints were compared with the critical values derived by Nuttall et al. (2003b). In more than $50 \%$ of the sites, salinity was higher than the critical value of $0.8 \mathrm{dS} / \mathrm{m}$ at depths below $0.6 \mathrm{~m}$. In about $50 \%$ of the sites, sodicity and boron were
Table 2. Correlation matrix for the coefficients of variation across different soil chemical and physical properties

Soil salinity (EC), exchangeable sodium percentage (ESP), boron (B), cation exchange capacity (CEC), and soil water $-15 \mathrm{kPa}(\mathrm{WP})$ at different depths, observed in soil samples from the Birchip region

\begin{tabular}{lrrrr}
\hline & \multicolumn{1}{c}{ EC } & ESP & B & CEC \\
\hline EC & 1 & & & \\
ESP & -0.32 & 1 & & \\
B & -0.16 & 0.98 & 1 & \\
CEC & -0.42 & 0.91 & 0.83 & 1 \\
WP & -0.094 & 0.97 & 0.99 & 0.85 \\
\hline
\end{tabular}

above the critical values of $19 \%$ and $24 \mathrm{mg} / \mathrm{kg}$ at depths below $0.6 \mathrm{~m}$.

\section{Simulation Expt 1}

A soil rooting distribution factor, i.e. relative root mass density, was calculated from the measured values of root mass in each layer, relative to the root mass density in the upper layer (0-0.1 m) at each of the 150 sites (Fig. 2). The 


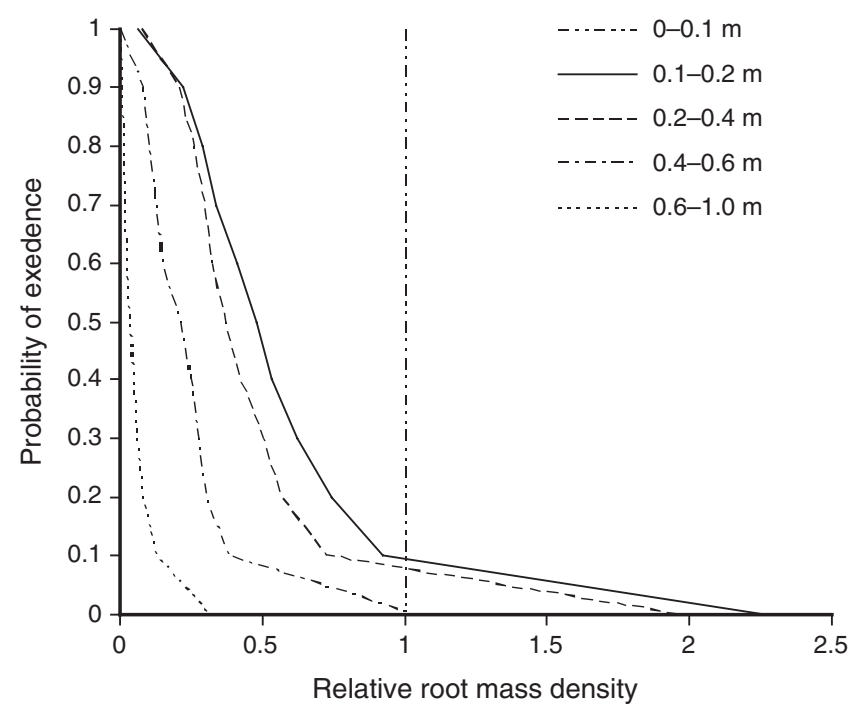

Fig. 2. Probability distribution for the root mass density in different soil layers relative to that in the $0-0.1 \mathrm{~m}$ layer for 150 sites around Birchip. After Nuttall et al. (2003b).

median root distribution factor (RDF) for the layer $0.1-0.2 \mathrm{~m}$ was 0.74 , for the layer $0.2-0.4 \mathrm{~m}$ was 0.47 , for the layer $0.4-0.6 \mathrm{~m}$ was 0.41 , and for the layer $0.6-1 \mathrm{~m}$ was 0.12 . To eliminate the effect of declining root mass density with depth, a standardised root expansion factor was derived for each soil layer. This factor was calculated relative to the RDF values observed in each layer at the site that produced the highest grain yield, i.e. $6 \mathrm{t} / \mathrm{h}$. At this site the values of salinity, sodicity, and boron were low in all soil layers.

The soil characteristic that best explained the observed variability in the root expansion factor among soil layers and sites was soil salinity. The values of the root expansion factor in the $0.4-1 \mathrm{~m}$ layer were inversely correlated with EC $(r=-0.59)$, soil sodicity $(r=-0.53)$, and soil boron $(r=-0.47)$. In this exercise we assumed that soil salinity was the main limiting factor for soil root exploration at depth. From the relationship shown in Fig. 3, we assumed that the root expansion factor had a value of 1 for EC below $0.68 \mathrm{dS} / \mathrm{m}$, and that it decreased hyperbolically to 0 at values of EC higher than $0.68 \mathrm{dS} / \mathrm{m}$ (Eqn 1):

$$
\text { if } \mathrm{EC}<0.68 \text {, Root expansion factor }=1
$$

$$
\text { if } \mathrm{EC} \geq 0.68 \text {, Root expansion factor }=\frac{2.06}{(1+2 \cdot \mathrm{EC})}-0.35
$$

Figure 4 shows the performance of the model APSIMWheat when 16 randomly selected sites around Birchip were simulated assuming: $(i)$ the observed root distribution within the soil profile at each site and measured values of WP as inputs to the model (Hypothesis A), (ii) ignoring the presence of subsoil constraints and using measured values of WP (control), (iii) calculating the root soil profile distribution

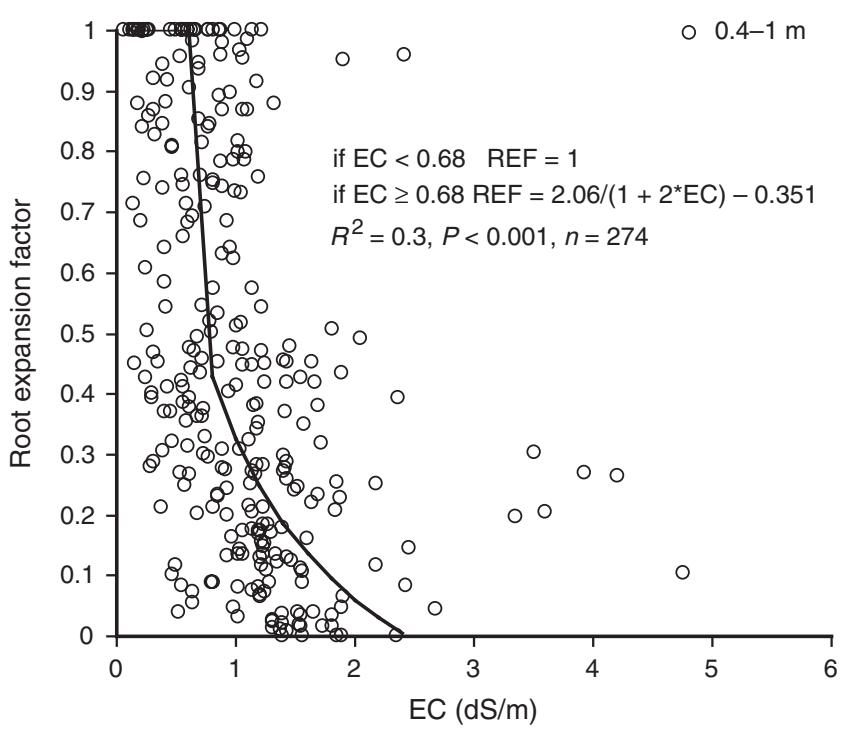

Fig. 3. Derived root expansion factor as a function of soil EC $(\mathrm{dS} / \mathrm{m})$.

from a function relating root distribution and EC $(\mathrm{dS} / \mathrm{m})$ (Hypothesis A), and (iv) calculating the value of the crop lower limit (parameter $l l$ in APSIM) for each soil layer, as a function of the EC $(\mathrm{dS} / \mathrm{m})$ as proposed by Sadras et al. (2003) (Hypothesis B). Simulated outputs were sensitive to the different assumptions and affected the degree of fit between observed and predicted values (Fig. 4). Assuming no limitation to root growth and the measured values of WP as the lower limit for soil water uptake by roots (control), the model explained only $43 \%$ of the observed variability in grain yield with a root mean squared deviation (RMSD) of $0.98 \mathrm{t} / \mathrm{ha}$ (Fig. 4b). Assuming the observed root distribution at each site and the measured values of LL15 as the lower limits for soil water uptake (Hyp. A), the model explained $70 \%$ of the observed variability in grain yield $(\mathrm{RMSD}=0.75 \mathrm{t} / \mathrm{ha}$ ) (Fig. 4a). This compared with $58 \%$ when a median root exploration factor calculated from the 150 sites was applied to the 16 simulated sites (Hyp. A) $(\mathrm{RMSD}=0.97 \mathrm{t} / \mathrm{ha}$ ) (not shown in Fig. 4), and to $60 \%$ when the root distribution was calculated from Eqn 1 (Hyp. A) $(\mathrm{RMSD}=0.9 \mathrm{t} / \mathrm{ha})$ (Fig. $4 c$ ). When the root exploration factor was set to 1 for all soil layers at all sites and the lower limit for soil water extraction was calculated as a function of the EC for each soil layer (Hyp. B) the model explained $65 \%$ of the observed variation in grain yield $(\mathrm{RMSD}=0.86 \mathrm{t} / \mathrm{ha}$ ) (Fig. $4 d$ ).

A more thorough analysis of the comparison between observed and simulated grain yield was done by subdividing the mean square deviation (MSD) into its squared bias (SB), squared difference between standard deviations (SDSD), and lack of correlation weighted by the standard deviations (LCS) (Fig. 5). Briefly, a high SB indicates large bias of the simulation from the measurement, a high SDSD indicates that the model failed to simulate the magnitude of the fluctuation 


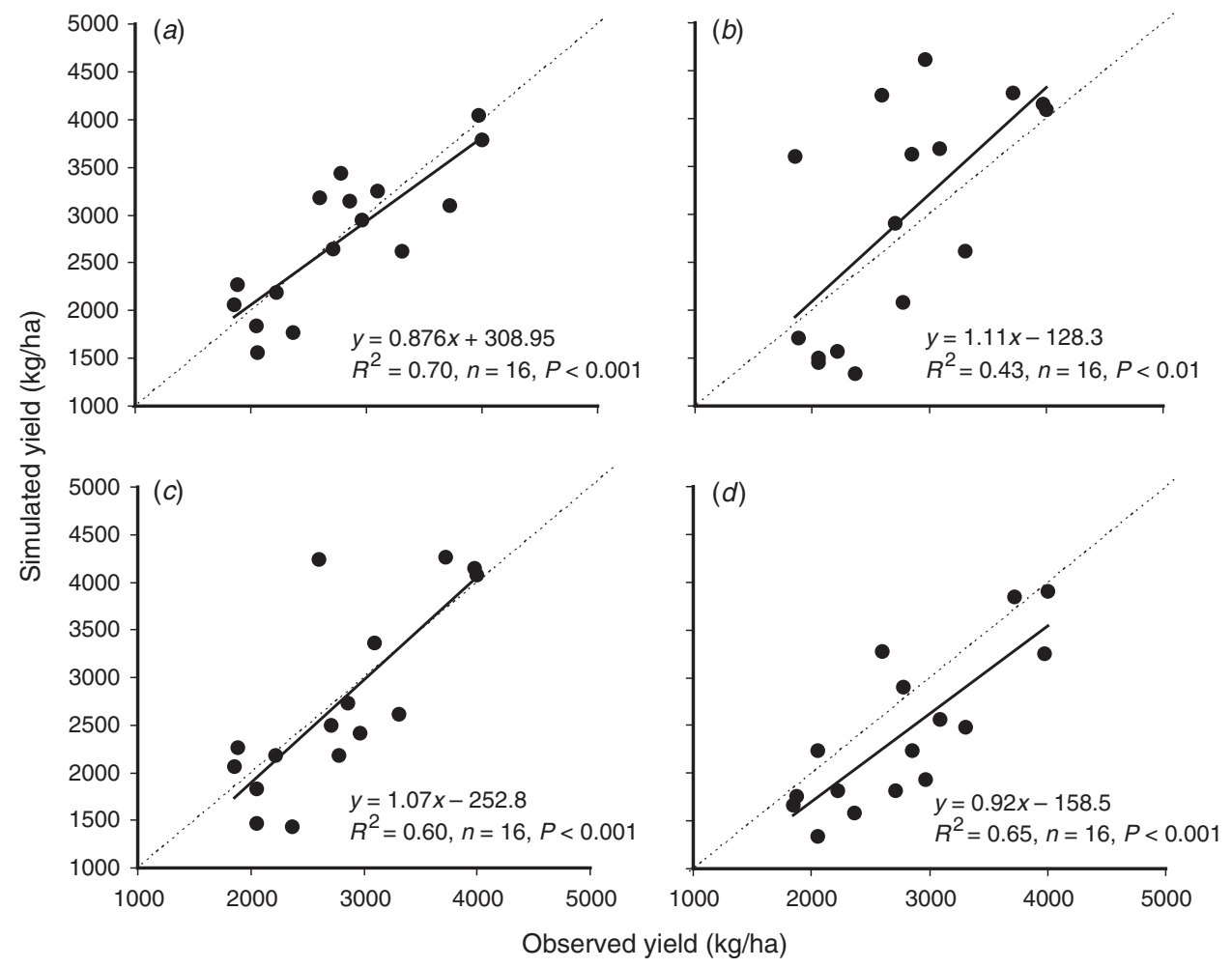

Fig. 4. Simulated $v$. observed wheat yields at 16 sites around Birchip in 1999. Simulated results were obtained after $(a)$ using observed root profile distributions as input in the model; $(b)$ ignoring the presence of subsoil constraints; $(c)$ estimating a potential root distribution factor as a function of soil salinity; and $(d)$ modifying the crop lower limit for soil water uptake as a function of soil salinity. After Nuttall et al. (2003b).

among the measurements, and a high LCS means that the model failed to simulate the pattern of the fluctuation across the measurements, i.e. lack of positive correlation.

The lack of fit $(1-r)$ and MSD were lowest in simulation using observed root distribution, and highest for the control simulation, for which subsoil constraints were ignored. Assuming the median root profile distribution of the 150 sites, or deriving the root profile distribution from $\mathrm{EC}$ values (SRF-EC in Fig. 5), gave intermediate results (Fig. 5). In general, the lack of positive correlation between observed and simulated results was the main component explaining the values of MSD. For Hypothesis B (LL-EC in Fig. 5), the bias and failure of the model to simulate the magnitude of the observed variability were also important. This indicated that other factors could have also been active as shown by a positive relationship between EC in the $0.4-0.6 \mathrm{~m}$ layer and the residuals between observations and simulated results assuming Hypothesis B (residuals $=381 * \mathrm{EC}-55, R^{2}=0.16$, $n=16, P<0.08)$.

Figure $6 a$ and $b$ shows the performance of the APSIMWheat model in simulating the soil water balance at Birchip and Brim, respectively, over 2 consecutive cropping seasons, assuming: ( $i$ ) the observed crop lower limit for soil water extraction (parameter $l l$ in APSIM) derived as the minimum soil water content observed in each soil layer during 2 consecutive cropping seasons (Observed CLL), (ii) root soil profile distribution factor derived from Eqn 1 (SRF), and (iii) the value of the crop lower limit (parameter $l l$ in APSIM) estimated for each soil layer as a function of EC (dS/m) as proposed by Sadras et al. (2003) (LL-EC). At both locations and for all soil depths, estimating the crop lower limit for soil water uptake using values of EC (Sadras et al. 2003) closely followed both the observed values (symbols), and the results from the simulations when the observed crop lower limit (Observed CLL) was used as input in the model. Assuming that salinity reduced root exploration according to Eqn 1, overestimated soil water availability at Birchip. At Brim, all tested assumptions gave similar results for the upper layers (Fig. $6 a$ and $b$ ), whereas in the deeper layers (Fig. $6 c$ and $d$ ) both approaches underestimated the crop lower limits observed in the field. Figure 7 illustrates that the approach using EC to estimate the crop lower limit was able to explain $68 \%$ of the variability in the average farm yields in Birchip and Brim. 

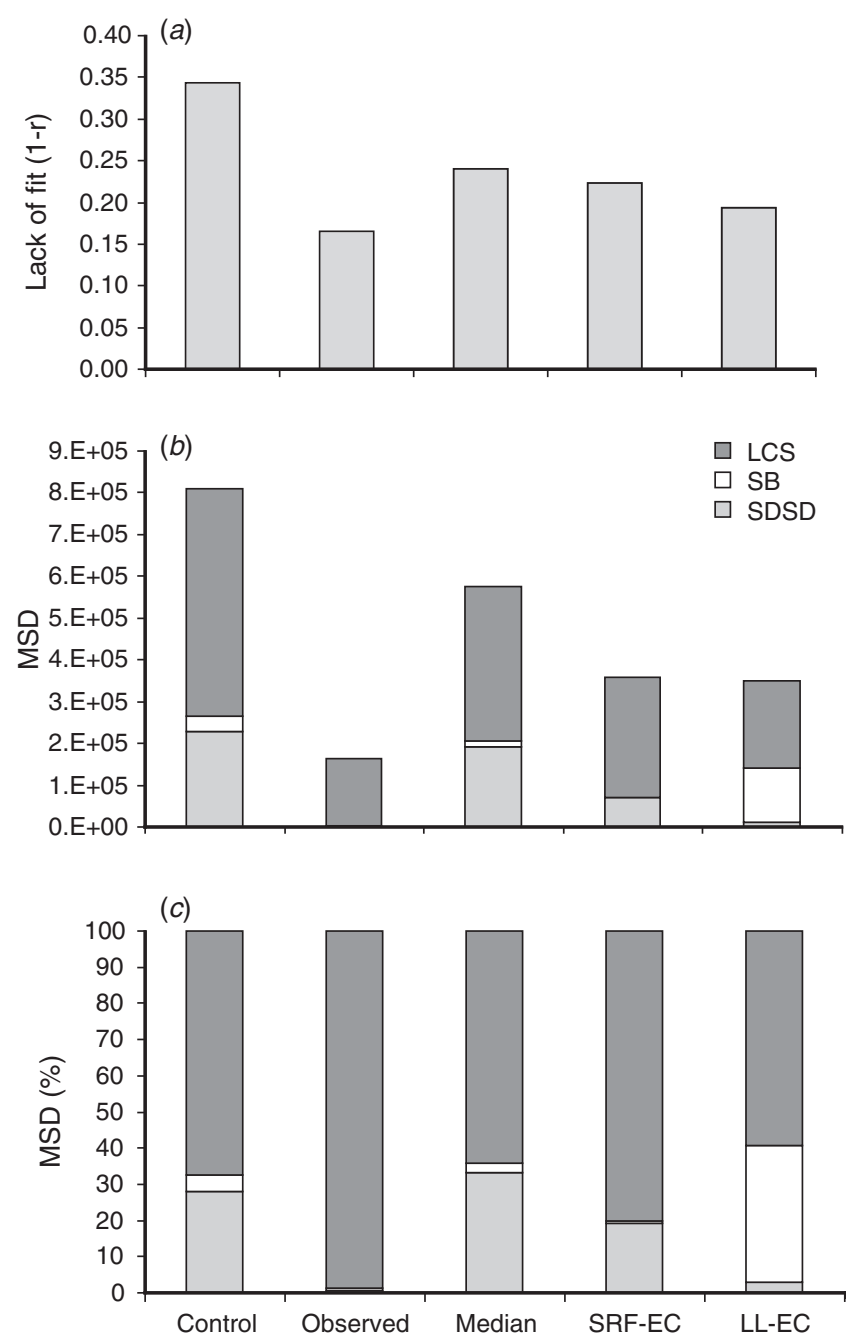

Fig. 5. Lack of fit $(a)$, and ( $b$ and $c$ ) partitioning of the mean square deviation (MSD) into squared difference between standard deviations (SDSD), bias (SB), and lack of positive correlation (LCS), for simulations ignoring the presence of subsoil constraints (Control), and simulations assuming: the observed root distribution (Observed), the median root distribution observed in the region (Median), a root distribution calculated as a function of the salinity of each soil layer (SRF-EC), and the changes in the lower limit for crop water uptake estimated from the soil salinity in each soil layer (LL-EC).

\section{Simulation Expt 2}

To study the importance of the interactions between subsoil constraints and climate variability, and quantify the economic effect of subsoil constraints in the southern Mallee of Victoria, we conducted long-term simulations assuming 3 levels of soil salinity: low (decile 1), regional median (decile 5), and high (decile 9), as derived from Fig. 1 $a$. The effect of soil salinity on crop growth and yield was modelled following the assumptions of Sadras et al. (2003). Figure 8, shows the simulated relationship between grain yield and in-crop rainfall for 2 contrasting levels of salinity (decile 5 and decile 9) for the period 1900-2002. The solid line in
Fig. 8 indicates an average 'rainfall water-use efficiency' and 'non-productive water loss' of $15.4 \mathrm{~kg} / \mathrm{mm}$ and $63 \mathrm{~mm}$ for a median level of salinity. These values are reduced by $12 \%$ and increased by $46 \%$, for a high salinity (decile 9) level, respectively. Figure 9 illustrates the relationship between the effect of subsoil salinity and in-crop rainfall. The effect is estimated as the ratio of simulated grain yield at high level to that at medium level. The response indicates that the effect of a severe subsoil constraint would be less during wetter seasons and that it is more likely to have greater impact during El Niño years than during La Niña years. Both the level of soil salinity and whether the season was defined as El Niño or as La Niña had an important effect on the probability distribution of gross margin (Fig. 10). With median levels of salinity, negative margins can be expected in this region once every 5 years over the period 1900-2002. However, for high salinity soils, losses can be expected up to once every 3 years, whereas for low salinity conditions there was only one loss every 20 years (Fig. 10a). When the season is defined either as El Niño or La Niña, these risks change dramatically (Fig. $10 b$ and $c$ ). During El Niño years the chance of making a loss is 50, 40, and 15\% for high-, median-, and low-salinity areas, respectively. During La Niña years the chances of making a loss are very small even in high-salinity areas (Fig. 10c).

\section{Discussion}

With this work we tested the predictive capacity of the model APSIM-Wheat for a region having soils with important physicochemical subsoil constraints; applied the APSIMWheat model to study the interactions between subsoil constraints and seasonal conditions; and estimated the economic effect that subsoil constraints have on wheat farming in the Victorian Mallee under different climatic scenarios.

\section{Soil constraints in the Birchip region}

Soils from the Victorian Mallee (Birchip region) are mostly Calcarosols with vertic subsoils (i.e. Vertic Calcarosols), which generally present gilgai microrelief(Imhof et al. 2003). Proportionally less important, Vertosols are found in some of the gilgai depressions (Imhof et al. 2003). In this region, spatial variability in crop water use and production is highly related to the presence of gilgaied plains with hummocks or rises, and associated variability in the depth at which high levels of salinity, sodicity, and boron are found. Generally, the shallower (Calviño and Sadras 1999) and the more intense the limitation (Munns 1996), the more severe will be the effect on the crop. Nuttall et al. $(2003 a, 2003 b)$ produced important advances in the description and extent of subsoil constraints in the southern Mallee region of Victoria, and Sadras et al. (2003) produced the first quantitative analysis of the effect of subsoil constraints on the water budget components of wheat in coarse-textured soils from the northern Mallee. 


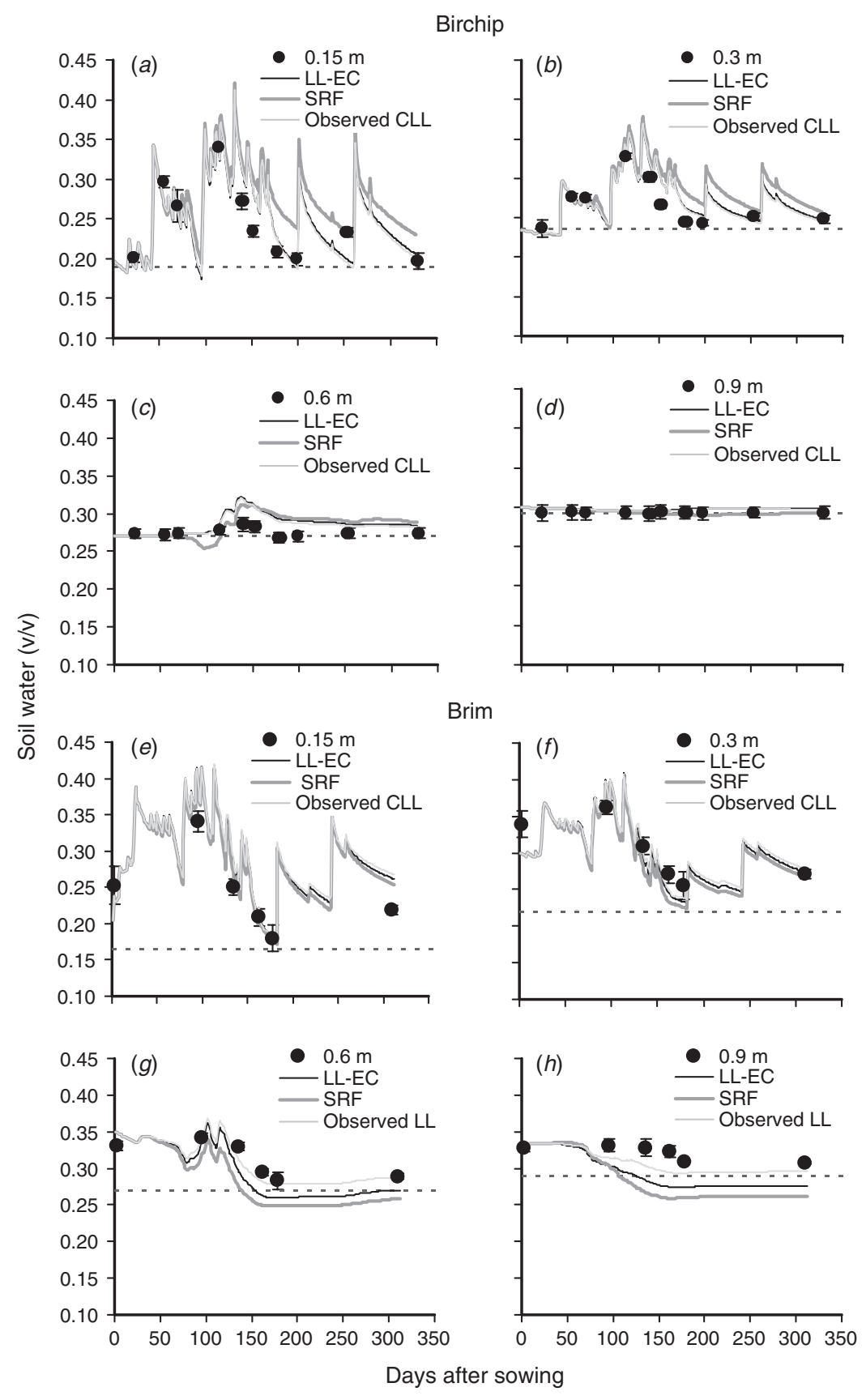

Fig. 6. Observed (symbols) and simulated (lines) volumetric soil water content at (a) $0.15 \mathrm{~m},(b) 0.3 \mathrm{~m},(c) 0.6 \mathrm{~m}$, and $(d) 0.9 \mathrm{~m}$ for a wheat crop during the 1993-94 season in Birchip, and $(e) 0.15 \mathrm{~m},(f) 0.3 \mathrm{~m},(g) 0.6 \mathrm{~m}$, and $(h) 0.9 \mathrm{~m}$ at Brim. Simulated results are derived assuming values of crop lower limit estimated from (i) soil salinity (LL-EC), (ii) a root distribution factor derived from soil salinity (SRF), and (iii) a crop lower limit (Observed CLL) estimated as in Dalgliesh and Foale (1998). The lowest soil water content observed in the field for each soil layer is included as a horizontal dashed line.

Critical thresholds for the effect of salinity $(8 \mathrm{dS} / \mathrm{m})$, and sodicity (19\%), were derived empirically from fig. 6 of Nuttall et al. (2003b), and are represented here in Fig. 1. Using these thresholds we found that more than $50 \%$ of the tested sites had salinity higher than the critical value in the $0.4-0.6 \mathrm{~m}$ layer, whereas in about $50 \%$ of the sites the values of sodicity and boron were above the critical values in the 0.6-1 m layer. In the work of Nuttall et al. (2003a) in the 


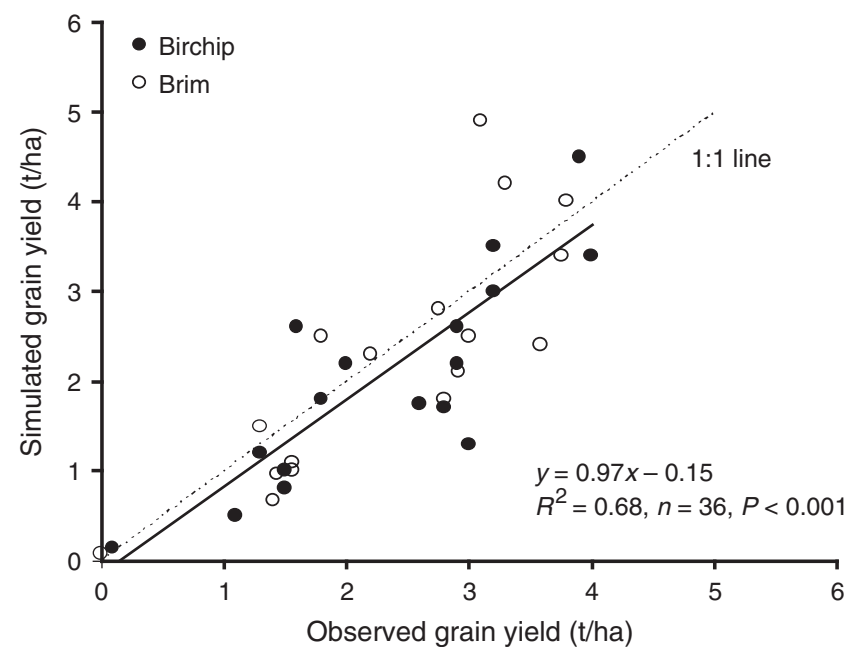

Fig. 7. Observed $v$. simulated average farm wheat yields for 2 farms at Brim and Birchip, for the period 1983-2002. Results for 1992 and 1993 were excluded due to effects of diseases and frost damage, respectively.

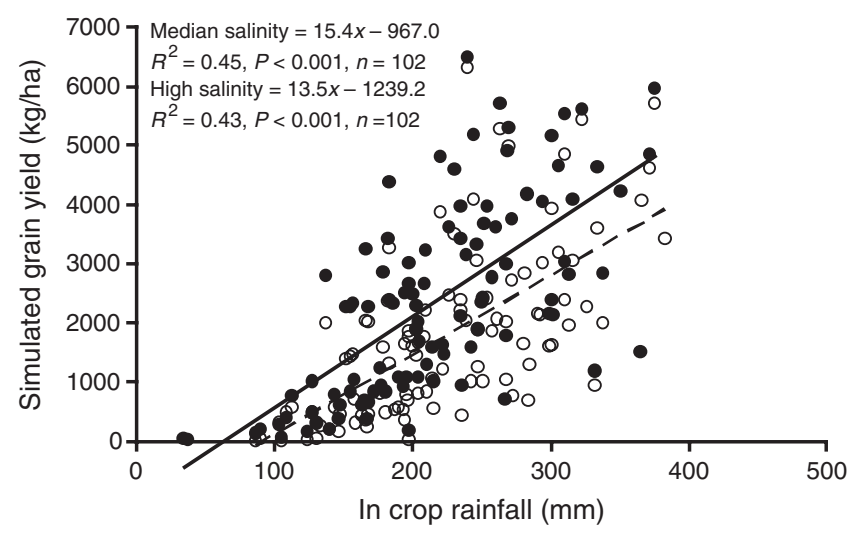

Fig. 8. Simulated grain yields as a function of in-crop rainfall assuming the median and high levels of salinity observed in the region.

Victorian Mallee as well as in Sadras et al. (2003) in the northern Mallee, salinity was identified as the main subsoil constraint. Both studies also presented interrelationships among $\mathrm{pH}$ and boron, salinity, and sodicity. These relationships were obtained by pooling information from a range of soil depths and locations, disregarding interrelationships between the parameters and the change in soil texture with soil depth as shown in Sadras et al. (2002, 2003). As an example, a simple correlation between the coefficients of variation for the different soil properties across Nuttall's data set, showed very little relationship between sodicity and salinity (Table 2). However, as previously found by Nuttall et al. (2003a) and Sadras et al. (2002), strong relationships can be expected between soil sodicity and boron concentration, cation exchange capacity, and textural properties such as the

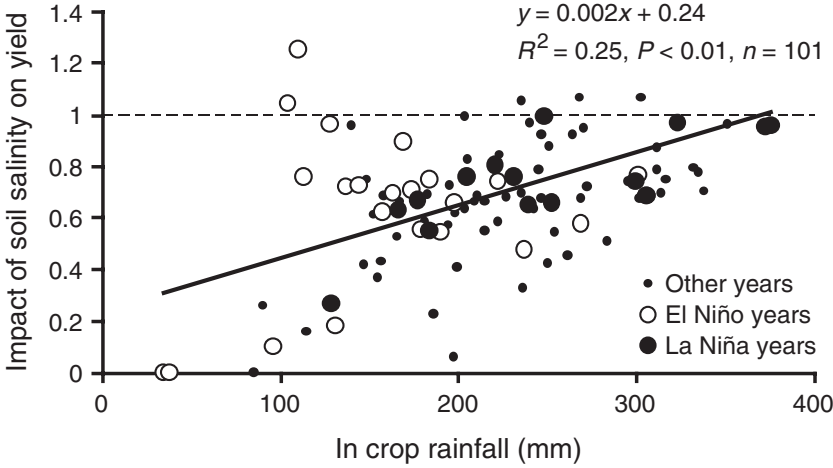

Fig. 9. Effect of soil salinity as a function of in-crop rainfall. The effect is estimated as the ratio of simulated grain yield at high soil salinity and that at median level of soil salinity.

laboratory-determined lower limit for soil water extraction. We think this supports the argument by Nuttall et al. (2003a) that the accumulation of salts in these soils might have occurred later than their alkalinisation, which limits our capacity to predict soil sodicity from rapid determinations of soil salinity.

\section{Performance of algorithms}

Unquestionably, subsoil constraints have to be taken into account in any model-based analysis of cropping on soils of the Victorian Mallee. In APSIM, the potential effect of subsoil properties on crop growth and production is generally assumed to be incorporated after measuring the lower limit of crop water extraction in the field under rainout shelters installed around anthesis (parameter $l l$ in APSIM) (Dalgliesh and Foale 1998). Sadras et al. (2003) determined the parameter $l l$ for APSIM more accurately by continuously recording soil water at different soil depths, over a period of more than 3 years, involving 2 canola crops and 1 wheat crop. Given the high variability in subsoil properties observed in the Victorian Mallee (Fig. 1 and Nuttall et al. 2003a), we suggest that any modelling exercise should not ignore existing within-paddock spatial variability in subsoil constraints. In order to account for such spatial variability and to capture its importance, algorithms and methods to capture such variability are required. It is possible that key variables could be rapidly and inexpensively collected using mobile electromagnetic induction techniques (Nelson and Ham 2000; O'Leary et al. 2003), and results translated into inputs for crop simulation models. To develop these algorithms we tested whether the effect of subsoil constraints on wheat yield in soils of the Victorian Mallee could be explained by assuming either $(a)$ that root exploration within a particular soil layer was reduced by the presence of toxic concentrations of salts; or $(b)$ that soil water uptake from a particular soil layer was reduced by high concentrations of salts through osmotic effects. 

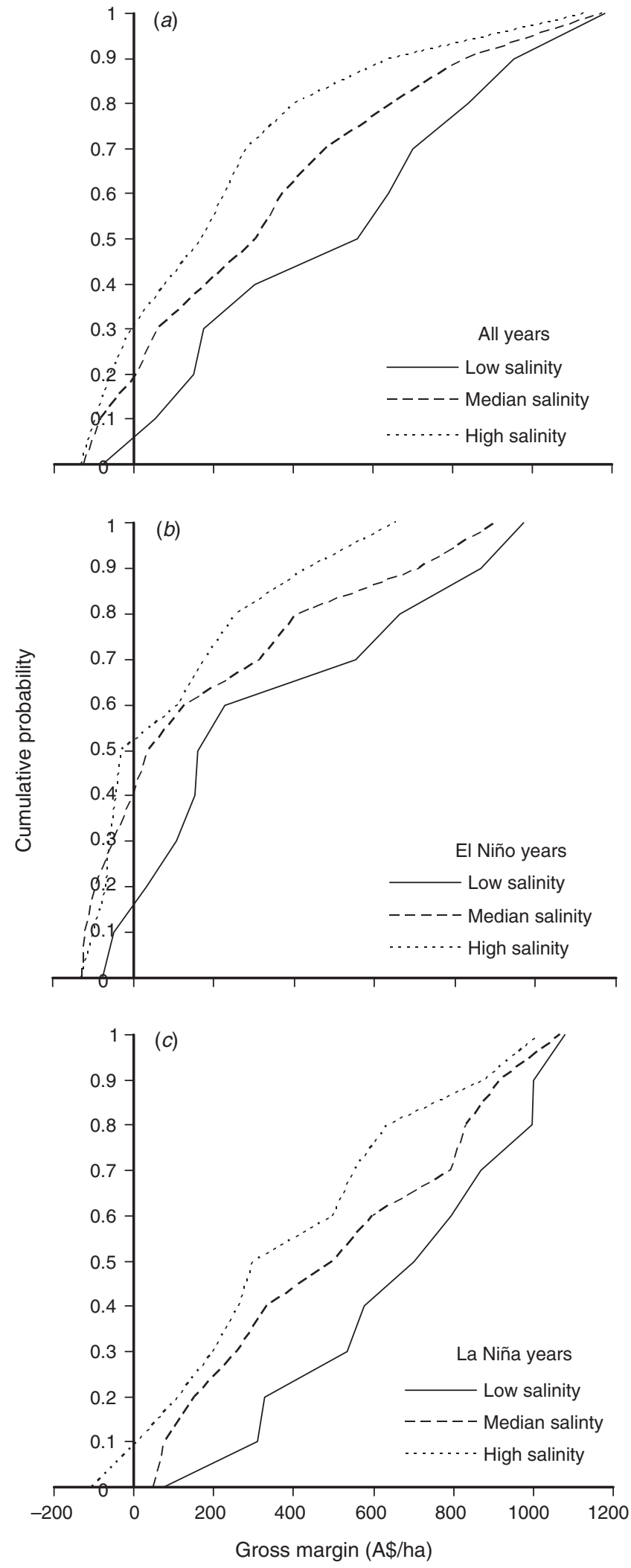

Fig. 10. Cumulative probabilities for the gross margin of growing wheat in the Victorian Mallee for 3 levels of salinity for $(a)$ all the years (102 years), (b) 24 El Niño years, and (c) 16 La Niña years.
The algorithms developed here and those of Sadras et al. (2003) improved the capacity of the APSIM-Wheat model to simulate wheat yield on soils having severe subsoil constraints (Fig. 4). The simulation analysis of wheat yield (Fig. 5) showed no clear advantage for Hypothesis $a$ or $b$. However, the soil water simulations suggested some advantage for Hypothesis $b$. Furthermore, the results shown in Fig. 7 indicate that this approach was also able to reliably reproduce average farm wheat yields when a decile 5 of soil salinity was assumed.

\section{Effect of subsoil constraints in the Victorian Mallee}

Crop responses to subsoil constraints, particularly salinity, are consistent with many symptoms of crop response to drought stress (Munns 2002). Common subsoil constraints found in western Victoria generally reduce the capacity of the crop to take up water, leading to reductions in growth and grain yield. In addition, under extreme conditions, accumulation of toxic levels of salts in leaf tissue can cause premature senescence, particularly of the older leaves, i.e. leaves that have been transpiring and accumulating salts for a longer time. In saline soils the root is the first organ to be in contact with a hostile environment; therefore, roots could also dramatically reduce their growth in saline soil layers. Reductions in root growth in saline solutions have been attributed to cell-wall hardening rather than to changes in turgor in maize (Neumann et al. 1994; Rodríguez et al. 1997). Plant responses to subsoil constraints have been observed to vary according to factors including crop variety, soil texture, agronomic practice, and climate (Ulery et al. 1998; Rengasamy 2002). Seasonal variations in the amount and distribution of rainfall could produce variation in the effect of subsoil constraints, as a result of changes in the pattern of root density distribution in the soil profile. In cereals, salinity can reduce the number of florets per ear, and alter the time of flowering and hence maturity (Munns and Rawson 1999). Similar effects can be observed under drought stress, which may complicate our capacity to separate both effects. Our modelling exercise reproduced the general observation, by farmers and consultants, that the effect of subsoil constraints is greater during dry seasons. This magnifies the effect of climate variability on productivity in soils from the Victorian Mallee. A similar association between seasonal rainfall and subsoil constraints was found for long-term simulations at Parafield in South Australia (Sadras et al. 2003). In their study, more complex patterns emerged when interactions were investigated over a broader range of rainfall environments, i.e. $200-600 \mathrm{~mm}$. They identified a seasonal rainfall threshold of $273 \mathrm{~mm}$. Above this rainfall level, the relationship between the effect of a subsoil constraint on grain yield and seasonal rainfall shifted from negative or neutral to positive. This agrees with our finding for the Birchip region, which has an average seasonal rainfall close to that threshold level $(257 \mathrm{~mm})$. A strong influence of the El Niño Southern 
Oscillation was also observed on the effect of soil salinity level on grain yield (Fig. 9) and gross margin (Fig. 10). The more frequent occurrence of drier seasons during El Niño years increased the chance of low or negative gross margins, whereas the more frequent wetter seasons during $\mathrm{La}$ Niña years significantly decreased this chance. These results indicate an important interaction between seasonal conditions and the intensity of the subsoil constraints.

\section{Conclusions}

On soils having subsoil constraints, climate variability and soil properties interact in such a way that rainfall information alone will provide an incomplete picture of the effect of climate variability on yield. This highlights the importance of the integration of soil properties and climate conditions with cropping systems models for risk management and farm planning. Simulation exercises in the Victorian Mallee should account for the presence of subsoil constraints. Here we have shown that methods developed for coarse-textured soils of the South Australian and Victorian Mallee can be extrapolated to highly saline and sodic, fine-textured soils of the Victorian southern-Mallee and northern Wimmera regions. However, we could not conclude whether limiting root exploration or rate of water extraction or both was the preferable approach for model adaptation.

\section{Acknowledgments}

This work was jointly supported by the Department of Primary Industries of Victoria and the Grains Research and Development Corporation (GRDC).

\section{References}

Asseng S, Fillery IRP, Anderson GC, Dolling PJ, Dunin FX, Keating BA (1998) Use of APSIM wheat model to predict yield, drainage, and $\mathrm{NO}_{3}{ }^{-}$leaching for a deep sand. Australian Journal of Agricultural Research 49, 363-377. doi: 10.1071/A97095

Asseng S, Fillery IRP, Dunin FX, Keating BA, Meinke H (2001) Potential deep drainage under wheat crops in a Mediterranean climate. I. Temporal and spatial variability. Australian Journal of Agricultural Research 52, 45-56. doi: 10.1071/AR99186

Calviño PA, Sadras V (1999) Interannual variation in soybean yield: interaction among rainfall, soil depth and crop management. Field Crops Research 63, 237-246. doi: 10.1016/S0378-4290 (99)00040-4

Carberry PS, McCown RL, Muchow RC, Dimes JP, Probert ME, Poulton PL, Dalgliesh NP (1996) Simulation of a legume ley farming system in northern Australia using the Agricultural Production Systems Simulator. Australian Journal of Experimental Agriculture 36, 1037-1048. doi: 10.1071/EA9961037

Dalgliesh N, Foale M (1998) 'Soil matters, monitoring soil water and nutrients in dryland farming.' (Agricultural Production Systems Research Unit: Toowoomba, Qld)

Goyne PJ, Meinke H, Milroy SP, Hammer GL, Hare JM (1996) Development and use of a barley crop simulation model to evaluate production management strategies in north-eastern Australia. Australian Journal of Agricultural Research 47, 997-1015. doi: 10.1071/AR9960997
Hammer GL, Holzworth DP, Stone R (1996) The value of skill in seasonal climate forecasting to wheat crop management in a region with high climatic variability. Australian Journal of Agricultural Research 47, 717-737. doi: 10.1071/ AR9960717

Hochman Z, Dalgliesh NP, Bell KL (2001) Contributions of soil and crop factors to plant-available soil water capacity of annual crops on Black and Grey Vertosols. Australian Journal of Agricultural Research 52, 955-961. doi: 10.1071/AR01004

Holloway RE, Alston AM (1992) The effects of salt and boron on growth of wheat. Australian Journal of Agricultural Research 43, 987-1001. doi: 10.1071/AR9920987

Imhof M, Rampant P, Ryan S, Abuzar M, Murphy A, Fay T, Martin J (2003) 'Soils of the Birchip cropping region. Companion notes for Birchip Field Day.' (Department of Primary Industries: Werribee, Vic.)

Kobayashi K, Salam MU (2000) Comparing simulated and measured values using mean squared deviation and its components. Agronomy Journal 92, 345-352. doi: 10.1007/s100870050043

McCown RL, Hammer GL, Hargreaves JNG, Holzworth DP, Freebairn DM (1996) APSIM: A novel software system for model development, model testing, and simulation in agricultural systems research. Agricultural Systems 50, 255-271. doi: 10.1016/0308$521 \mathrm{X}(94) 00055-\mathrm{V}$

Meinke H, Hochman Z (2000) Using seasonal climate forecasting to manage dryland crops in northern Australia - experiences from the 1997-98 seasons. In 'Applications of seasonal climate forecasting in agriculture and natural ecosystems - the Australian experience'. (Eds GL Hammer, N Nicholls, C Mitchell) pp. 149-165. (Kluwer: Dordrecht, The Netherlands)

Munns R (1996) Physiological processes limiting plant growth in saline soils: some dogmas and hypothesis. Plant, Cell and Environment 16, $15-24$.

Munns R (2002) Comparative physiology of salt and water stress. Plant, Cell and Environment 25, 239-250. doi: 10.1046/j.00168025.2001.00808.x

Munns R, Rawson HM (1999) Effect of salinity on salt accumulation and reproductive development in the apical meristem of wheat and barley. Australian Journal of Plant Physiology 26, 459-464.

Nelson PN, Ham GJ (2000) Exploring the response of sugar cane to sodic and saline conditions through natural variation in the field. Field Crops Research 66, 245-255. doi: 10.1016/S0378-4290 (00)00077-0

Neumann PM, Azaizeh H, Leon D (1994) Hardening of root cell walls: a growth inhibitory response to salinity stress. Plant, Cell and Environment 17, 303-309.

Nuttall JG, Armstrong RD, Connor DJ, Matassa VJ (2003a) Interrelationships between edaphic factors potentially limiting cereal growth on alkaline soils in north-western Victoria. Australian Journal of Soil Research 41, 277-292. doi: 10.1071/SR02022

Nuttall JG, Armstrong RD, Connor DJ (2003b) Evaluating physicochemical constraints of Calcarosols on wheat yield in the Victorian southern Mallee. Australian Journal of Agricultural Research 54, 487-497. doi: 10.1071/AR02168

O'Leary GJ, Connor DJ (1996a) A simulation model of the wheat crop in response to water and nitrogen supply: I. Model construction. Agricultural Systems 52, 1-29. doi: 10.1016/0308-521X (96)00003-0

O'Leary GJ, Connor DJ (1996b) A simulation model of the wheat crop in response to water and nitrogen supply: II. Model validation. Agricultural Systems 52, 31-55. doi: 10.1016/0308$521 \times(96) 00002-9$ 
O'Leary GJ, Grinter V, Mock I (2004) Optimal transect spacing for EM38 mapping for dryland agriculture in the Murray Mallee, Australia. In 'Proceedings of the 4th International Crop Science Congress'. Brisbane, Qld. http://www.cropscience.org.au/icsc2004/ poster/1/6/493_olearyg.htm, verified 24 January 2005.

O'Leary GJ, Ormesher D, Wells M (2003) Detecting subsoil constraints on farms in the Murray Mallee. In 'Proceedings of the 11th Australian Agronomy Conference'. Geelong, Vic. (Australian Society of Agronomy, ISBN 0-9750313-0-9) (http://www.regional.org.au/au/asa/2003/c/15/oleary.htm, verified 7 March 2003)

Rengasamy P (2002) Transient salinity and subsoil constraints to dryland farming in Australian sodic soils: a review. Australian Journal of Experimental Agriculture 42, 351-361. doi: 10.1071/EA01111

Robertson MJ, Carberry PS, Lucy M (2000) Evaluation of a new cropping option using a participatory approach with onfarm monitoring and simulation: a case study of spring-sown mungbeans. Australian Journal of Agricultural Research 51, 1-12. doi: 10.1071/AR99082
Rodríguez HG, Roberts JKM, Jordan WR, Drew MC (1997) Growth, water relations, and accumulation of organic and inorganic solutes in roots of maize seedlings during salt stress. Plant Physiology 113, 881-893.

Sadras V, Baldock J, Roget D, Rodriguez D (2003) Measuring and modelling yield and water budget components of wheat crops in coarse-textured soils with chemical constraints. Field Crops Research 84, 241-260. doi: 10.1016/S0378-4290(03)00093-5

Sadras V, Roget DK, O'Leary GJ (2002) On-farm assessment of environmental and management constraints to wheat yield and rainfall use efficiency in the Mallee. Australian Journal of Agricultural Research 53, 587-598. doi: 10.1071/AR01150

Ulery AL, Teed JA, van Genuchten MT, Shannon MC (1998) SALTDATA: a database of plant yield response to salinity. Agronomy Journal 90, 556-562.

Manuscript received 18 June 2004, accepted 14 February 2005 